\title{
Sonotrodes for Ultrasonic Welding of Titanium/CFRP-Joints-Materials Selection and Design
}

\author{
Moritz Liesegang ${ }^{1, *(\mathbb{D})}$, Yuan $\mathrm{Yu}^{1}{ }^{1}$, Tilmann Beck ${ }^{1}$ and Frank Balle ${ }^{2}$ (D) \\ 1 Institute of Materials Science and Engineering, Technische Universität Kaiserslautern, \\ 67653 Kaiserslautern, Germany; yuanyu@rhrk.uni-kl.de (Y.Y.); beck@mv.uni-kl.de (T.B.) \\ 2 Walter-and-Ingeborg-Herrmann Chair for Power Ultrasonics and Engineering of Functional Materials, \\ Department of Sustainable Systems Engineering (INATECH), Faculty of Engineering, University of Freiburg, \\ 79110 Freiburg, Germany; frank.balle@inatech.uni-freiburg.de \\ * Correspondence: liesega@mv.uni-kl.de
}

check for updates

Citation: Liesegang, M.; Yu, Y.; Beck, T.; Balle, F. Sonotrodes for Ultrasonic Welding of

Titanium/CFRP-Joints-Materials Selection and Design. J. Manuf. Mater. Process. 2021, 5, 61. https://doi.org/ 10.3390/jmmp5020061

Academic Editor: Steven Y. Liang

Received: 1 May 2021

Accepted: 9 June 2021

Published: 12 June 2021

Publisher's Note: MDPI stays neutral with regard to jurisdictional claims in published maps and institutional affiliations.

Copyright: (c) 2021 by the authors. Licensee MDPI, Basel, Switzerland. This article is an open access article distributed under the terms and conditions of the Creative Commons Attribution (CC BY) license (https:// creativecommons.org/licenses/by/ $4.0 /)$.

\begin{abstract}
Ultrasonic welding of titanium alloy Ti6Al4V to carbon fibre reinforced polymer (CFRP) at $20 \mathrm{kHz}$ frequency requires suitable welding tools, so called sonotrodes. The basic function of ultrasonic welding sonotrodes is to oscillate with displacement amplitudes typically up to $50 \mu \mathrm{m}$ at frequencies close to the eigenfrequency of the oscillation unit. Material properties, the geometry of the sonotrode, and the sonotrode tip topography together determine the longevity of the sonotrode. Durable sonotrodes for ultrasonic welding of high-strength joining partners, e.g., titanium alloys, have not been investigated so far. In this paper, finite element simulations were used to establish a suitable design assuring the oscillation of a longitudinal eigenmode at the operation frequency of the welding machine and to calculate local mechanical stresses. The primary aim of this work is to design a sonotrode that can be used to join high-strength materials such as Ti6Al4V by ultrasonic welding considering the longevity of the welding tools and high-strength joints. Material, sonotrode geometry, and sonotrode tip topography were designed and investigated experimentally to identify the most promising sonotrode design for continuous ultrasonic welding of Ti6AlV4 and CFRP. Eigenfrequency and modal shape were measured in order to examine the reliability of the calculations and to compare the performance of all investigated sonotrodes.
\end{abstract}

Keywords: ultrasonic welding; sonotrodes; hybrid joining; modal analysis; titanium/CFRP; multimaterial-design

\section{Introduction}

The performance of components for aeronautical or automotive industries is constantly being improved. In particular, there is a high demand for combinations of different material classes in form of hybrid joints, e.g., between metals and polymer composites to reduce component weight or to improve functionality in order to increase efficiency [1,2]. Ultrasonic welding is one promising technique to realise these hybrid joints. So far, ultrasonic welding is mostly used in the packaging industry to reliably join polymers quickly and costeffectively [3] or to join soft non-ferrous metals such as aluminium and copper for electrical applications [4]. Regardless of the ultrasonic welding type, the sonotrode must induce a sufficient amount of welding energy into the joining zone by oscillation in contact with the upper joining partner. Specific requirements of the sonotrode design have to be considered as the sonotrodes may have to resist high temperatures, considerable mechanical loads, and external influences, depending on the requested application and environment. Ultrasonic welding of hybrid material systems, such as metal/CFRP joints, has been a focus of research during the last decade. For example, aluminium/CFRP joints have been investigated [5-7]. In addition, several multi-metal combinations such as aluminium and magnesium, copper, steel or titanium have been ultrasonically welded [8-13]. Ultrasonically welded Ti6Al4V/CF-PEEK hybrid joints are part of current aviation research programmes [14]. Due to its high strength 
and hardness as well as relatively low thermal conductivity, titanium is a desirable but challenging upper joining partner, i.e., contacting the sonotrode. Dissimilar metal/titanium joints have been investigated in the past, but in contrast to this work, titanium was the lower joining partner during ultrasonic welding [8,15]. During the ultrasonic welding of Ti alloys as the upper joining partner, the sonotrode has to resist cyclic loads and temperatures up to $700^{\circ} \mathrm{C}$ at the sonotrode tip [14]. Hence, suitable materials and sonotrode geometries have to be considered in order to achieve reproducible high joint strength and longevity of the tools. Neppiras [16] investigated available sonotrode materials, sonotrode design, transducers for metal welding, and very high cycle fatigue testing of metals using an ultrasound transducer in 1960. A detailed overview about requirements and characteristics of ultrasonic welding sonotrodes is given in his work. Eigenfrequencies $\omega_{0}$ and acoustic transmission have been calculated in the past by solving the equation of motion for rod-shaped tapered sonotrodes [16]. Further investigations of similar rod-shaped sonotrodes were also performed by solving the equation of motion and by the finite element method (FEM). All results showed that the shape of the tapering affects acoustic transmission and mechanical stress [17-22]. Nanu et al. [20] measured frequencies and displacement amplitudes along the acoustic system to determine nodal points for clamping without changing the required acoustic properties, such as amplitude and modal frequency. Regarding materials selection for sonotrodes, Neppiras [16] considered mass density and velocity of sound in order to calculate the acoustic behaviour. Fatigue and damping behaviour were compared between the investigated sonotrode materials. Nevertheless, systematic investigations regarding materials selection for ultrasonic tools such as sonotrodes in general are rare. Commercially used sonotrode materials have been investigated by Emmer et al. $[23,24]$ who examined sonotrodes made from the tool steel CPM10V, $16 \mathrm{MnCr} 5$ and the metal matrix composite Ferrotitanit WFN in relation to displacement amplitude and microstructural effects. CPM10V showed the finest microstructure and hence, potentially, the most homogeneous mechanical and acoustic properties $[23,24]$. Besides mechanical properties of the used material, acoustic characteristics of sonotrodes are strongly dependent on geometry, especially the mass distribution along the axis of oscillation [25]. Hence, acoustic and mechanical properties, as well as geometrical design, have to be considered for ultrasonic tools. Mode coupling, degenerated modes, and mode interactions are described in several publications as superimposition of neighbouring modes [18,26-31]. Usually, ultrasonic tools are supposed to oscillate at one certain frequency in one isolated requested mode, e.g., the longitudinal mode at $20 \mathrm{kHz}$. Mode interaction may cause increased stresses during oscillation and an unequal distribution of amplitude at the sonotrode tip. Superposition of modes can be prevented by choosing an appropriate geometry to achieve a sufficient distance between the modes, e.g., $1000 \mathrm{~Hz}$ proposed in previous publications [18,26-31]. Nonetheless, there is a need for superimposition of modes in some cases, such as ultrasonic drilling tools [30,32], or sonotrodes that operate in a combined longitudinal-torsional mode [33-35].

To join Ti-alloys to CFRP joints by continuous ultrasonic metal welding, durable high performance sonotrodes are required. In the research presented, concepts of alternative materials and geometries were investigated to establish the most suitable sonotrode design to successfully join Titanium alloys. The required properties for robust ultrasonic welding sonotrodes are summarised in Figure 1. The primary aim of the work presented in this paper, is to enable high performance materials to be welded by power ultrasonics, in general and to guarantee a durable process corresponding to long lasting welding tools and highstrength joints. Materials selection, design of geometry and sonotrode tip, as well as stress analysis, are important considerations during the design process. As part of the design process, theoretical modal analysis was performed by FEM followed by experimental modal analysis after manufacturing the sonotrodes and after thermal treatment for comparison. 


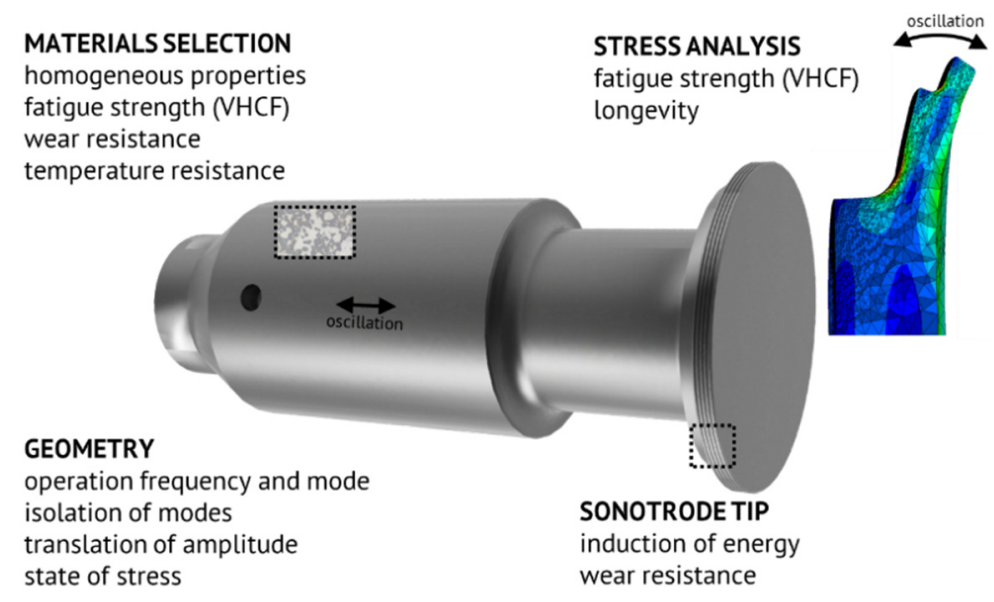

Figure 1. Fundamental requirements for durable ultrasonic welding sonotrodes.

\section{Materials and Methods}

The first step of the development of novel sonotrodes is the materials selection, followed by the design of the sonotrode geometry. As an important part of the design process, modal frequencies and mechanical stresses were calculated using two separate finite element (FE) models for each investigated material. Experimental modal analysis was performed for all sonotrodes by laser doppler vibrometry. The performance of suitable sonotrodes was assessed by welding experiments, considering the achieved joint strength, which was determined by tensile shear tests.

The chronological procedure of the development process of sonotrodes is listed below and described in the following subsections:

1. Materials selection

2. Design of the sonotrode geometry:

a. Theoretical modal analysis (FEM model I)

b. Calculation of mechanical stresses (FEM model II)

3. Experimental modal analysis and validation of the oscillation behaviour

4. Welding experiments

\subsection{Materials Selection and Characterization}

Promising materials were selected considering their mechanical properties such as hardness, strength or toughness, as extensively described in 0. Besides Young's modulus, mass density and Poisson's ratio, the fatigue strength was considered. Therefore, the fatigue strength of the selected materials was characterised by ultrasonic fatigue testing system $(20 \mathrm{kHz})$ close to ambient temperature up to an ultimate number of cycles of $2.5 \times 10^{9}$ to estimate the very high cycle fatigue (VHCF) behaviour (see [36,37]). The samples were tested in pulse/pause-sequences of $2500 \mathrm{~ms} / 500 \mathrm{~ms}$, leading to an effective testing frequency of $16.6 \mathrm{kHz}$. The pulse/pause mode allows to keep the sample temperature close to $17^{\circ} \mathrm{C}$ with maximum increase in temperature of $2^{\circ} \mathrm{C}$, each cycle. All fatigue experiments were performed with closed-loop control of the specimen displacement, measured by LaserDoppler vibrometry. The design of the sample geometry to assure a longitudinal oscillation at $20 \mathrm{kHz}$ eigenfrequency and to determine the relation between von Mises stress and displacement amplitude was performed by Simulia Abaqus using the FE model shown in Figure 2a. The manufactured samples including the polished gauge section between the dashed lines are shown in Figure 2b. 

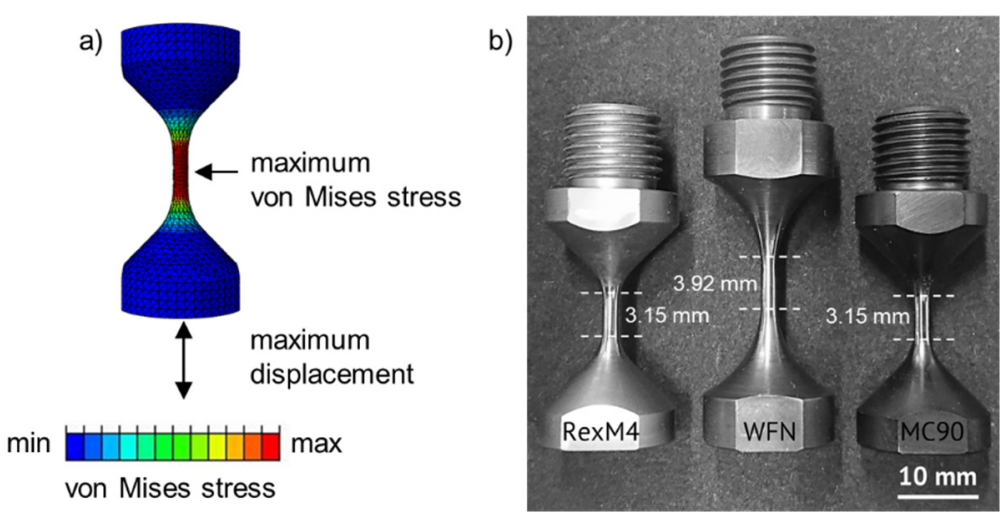

Figure 2. VHCF-samples of sonotrode materials RexM4, WFN and MC90: (a) FE model of a longitudinal oscillation to determine eigenfrequencies and mechanical stresses, (b) manufactured samples including the polished gauge section between the dashed lines.

\subsection{Design of the Sonotrode Geometry}

The geometry was developed for obtaining a longitudinal mode at $20 \mathrm{kHz}$ and keeping the maximum von Mises stresses below a limit of $350 \mathrm{MPa}$ at a maximum displacement amplitude of $50 \mu \mathrm{m}$, which was assumed to be sufficient for ultrasonic welding of titanium and confirmed in [14]. An initial sonotrode geometry was determined considering that sonotrodes typically have a full or half wavelength shape to ensure maximum displacement at the sonotrode tip [38]. The basic shape of all investigated sonotrodes contained sections with different diameters and masses to achieve a suitable amplitude. Rotary sonotrodes are oscillation systems of at least two mass sections- $\mathrm{S}_{\mathrm{I}}$ and $\mathrm{S}_{\mathrm{III}}$ (see Figure 10). The mass distribution along the sonotrode determines the impact of each section on the modal frequencies.

FE model I was used to determine the modal frequencies using linear perturbation analysis in Simulia Abaqus. Due to the rotational symmetric shape, tetrahedral elements (C3D10) were suitable to mesh the sonotrode using an element size of approximately $3 \mathrm{~mm}$. The modal frequencies were determined solving the eigenvalues of the equation of motion by, considering Young's modulus, Poisson's ratio and mass density. Figure 3 shows model I for the determination of modal frequencies including the whole sonotrode. The initial geometry was iteratively adjusted after modal analysis for obtaining a longitudinal oscillation in an eigenmode at $20 \mathrm{kHz}$.

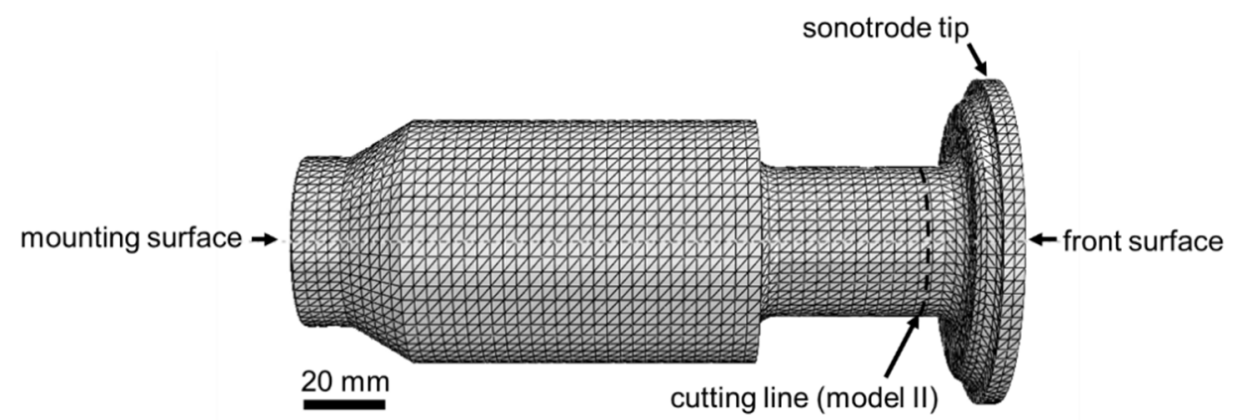

Figure 3. FE model I to determine modal frequencies by linear perturbation in Simulia Abaqus.

The mechanical stress distribution was considered in a second FE model (model II). Von Mises stresses were calculated in a standard, pre-implemented static procedure in Simulia Abaqus for a displacement of $50 \mu \mathrm{m}$. As dynamic calculations of the whole vibrating sonotrode showed exactly the same results in preliminary calculations, the less time-consuming static method was applied and only the sonotrode front (FE model II) where the highest stresses occur was considered (see Figure 4). Young's modulus and Poisson's ratio are included in this model. 


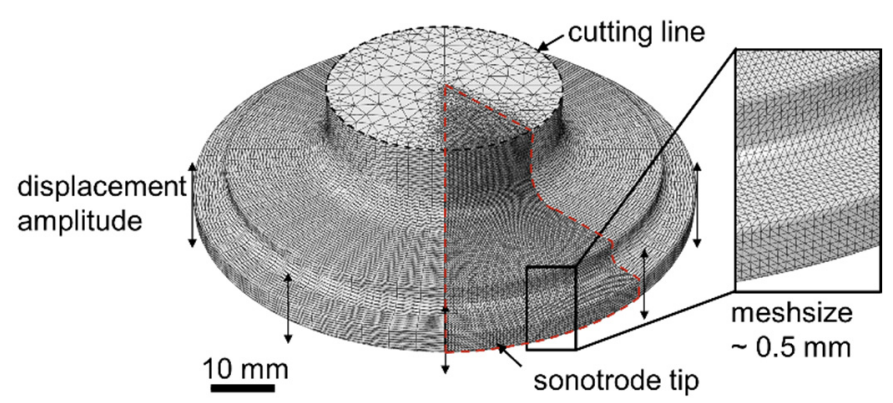

Figure 4. FE model II to determine mechanical stresses for a $50 \mu \mathrm{m}$-displacement of the sonotrode tip.

The cutting lines in Figures 3 and 4 indicate the boundaries of the sonotrode tip section, considered in model II. The surface perpendicular to the cutting line is locked for movement and rotation in all directions. Solely the surface of the sonotrode tip is displaced by a displacement of $50 \mu \mathrm{m}$ to achieve the same deformation behaviour as the longitudinal mode used for welding at $20 \mathrm{kHz}$. To reach high accuracy in the stress analysis, a convergence study was performed revealing a suitable average element size of $0.5 \mathrm{~mm}$. To calculate the stress state within reasonable time, this small mesh size was only applied to one section of the sonotrode front indicated in Figure 3. If the mechanical stress exceeded a limit of $350 \mathrm{MPa}$, diameters and radii were changed followed by a recalculation of the modal frequencies in model I. This procedure was repeated until the abovementioned prerequisites-eigenfrequency and stress level-were fulfilled. To estimate the effect of sonotrode tip topography, which affects the joint strength and the sonotrode wear [39], the mechanical stress caused by the displacement amplitude during the welding process was calculated by FEM. A pyramidal sonotrode tip was compared to a knurled topography. The model of the sonotrode tips, the imprint of the sonotrode tip in Ti6Al4V and a cross section of the sonotrode tip in contact with Ti6Al4V are summarized in Figure 5. The mechanical properties considered in the FE model are listed in Table 1. An ideal elastic behaviour was assumed for this model to focus on the impact of the sonotrode tip topography on the stress distribution without considering stress redistributions due to plastic deformation. The Ti6Al4V sheet representing the upper joining partner was fixed in all directions against movement while the sonotrode was displaced. The sonotrode tip was in frictional contact to the Ti6Al4V assuming a friction coefficient of 0.5 [40].

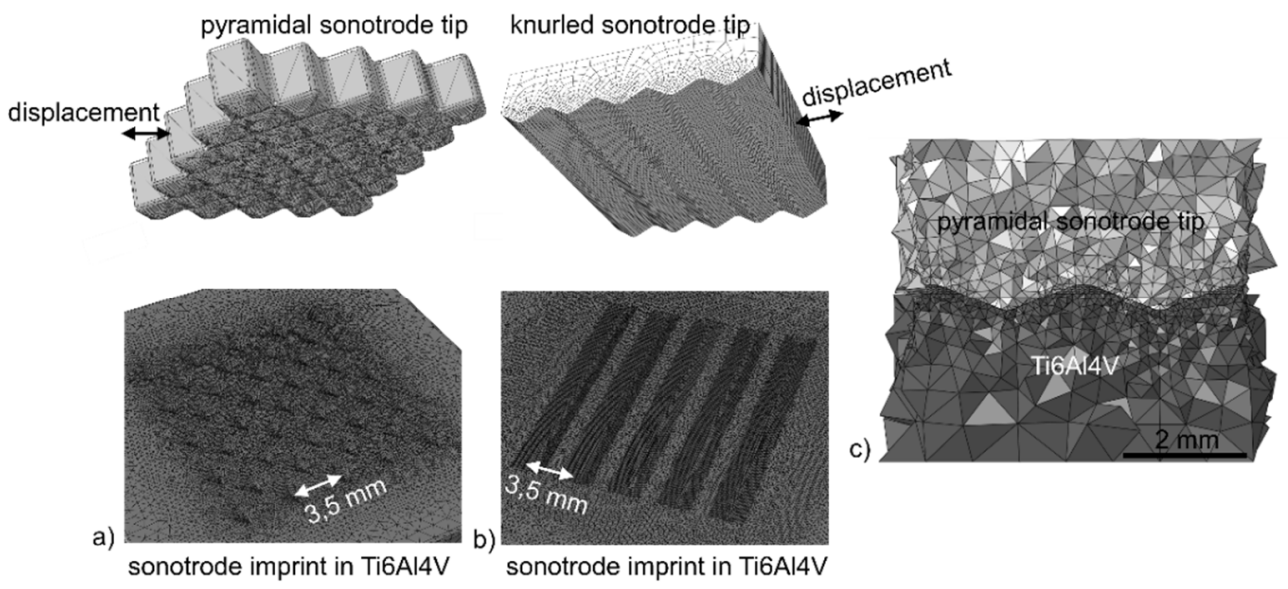

Figure 5. FE model of (a) a pyramidal and (b) a knurled sonotrode tip to estimate the effect of sonotrode tip topography on the mechanical stress caused by the displacement amplitude during the welding process shown in (c) a cross section of Ti6Al4V intruded by the sonotrode tip. 
Table 1. Mechanical properties considered for the FE model to estimate the effect of sonotrode tip topography on the mechanical stress.

\begin{tabular}{|c|c|c|}
\hline & Ti6Al4V [41] & Sonotrode Tip [42] \\
\hline Young's modulus in GPa & 110.0 & 223.3 (MC90) \\
\hline Poisson's ratio & 0.34 & 0.20 (MC90) \\
\hline Friction coefficient & & \\
\hline
\end{tabular}

\subsection{Modal Analysis}

Before the first usage of the sonotrodes, which were manufactured according to the simulation results, the modal frequencies were determined experimentally using Laser Doppler vibrometry (LDV: Polytec OFV-552 and 3D LDV: Polytec PSV-500). The oscillation was induced by a piezo actuator attached at the mounting surface (see Figure 3), applying a frequency range from $10 \mathrm{kHz}$ to $25 \mathrm{kHz}$. The loose contact between sonotrode and actor allows to measure solely the acoustic behaviour of the sonotrode, in contrast to measurements with sonotrodes installed into the welding system. The resulting movement of the front surface of the sonotrode was detected. Fast Fourier Transformation (FFT) was used to determine the modal frequencies. A 3D LDV allowed the identification of the modal shapes by combination of modal frequency and velocity profile at the sonotrode tip. The principal experimental setup for modal analysis by Laser-Doppler vibrometry is shown in Figure 6. The VHCF-samples investigated in this work were characterized analogously before testing.

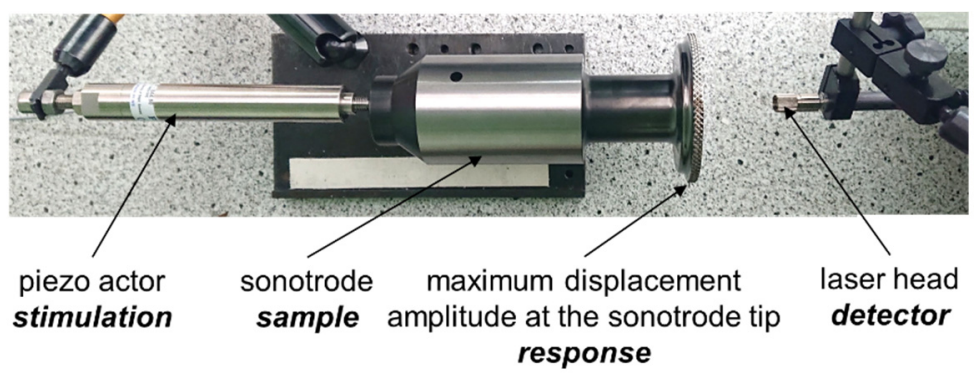

Figure 6. Experimental setup for modal analysis by Laser-Doppler vibrometry in principal.

\subsection{Welding Experiments and Mechanical Testing}

Welding experiments were performed using a $20 \mathrm{kHz}$ rotary ultrasonic welding machine Branson Ultraseam 20 (see Figure 7). The oscillation unit of the welding machine used in this work is shown in Figure $7 \mathrm{~b}$. The converter provides a maximum displacement amplitude of $12 \mu \mathrm{m}$ gained by booster I to $19.2 \mu \mathrm{m}$. Booster II is surrounded by the bearing of the rotatable oscillation unit and has no gain, meaning that the sonotrode transmission has to be minimum 1:2.6 to achieve the requested amplitude of $50 \mu \mathrm{m}$.

The performance of each sonotrode was determined on the basis of the tensile shear strength achieved for the welded Ti6Al4V/CFRP joints, which indicated the joint strength in $\mathrm{N} / \mathrm{mm}$ (ultimate tensile shear force per length of the welding seam). The tensile shear tests were performed using a Schenk tensile testing machine with a velocity of $3 \mathrm{~mm} / \mathrm{min}$ and a load parallel to the sheet planes and perpendicular to the welding direction. For each sonotrode and sonotrode tip topography, three specimens were tested. 


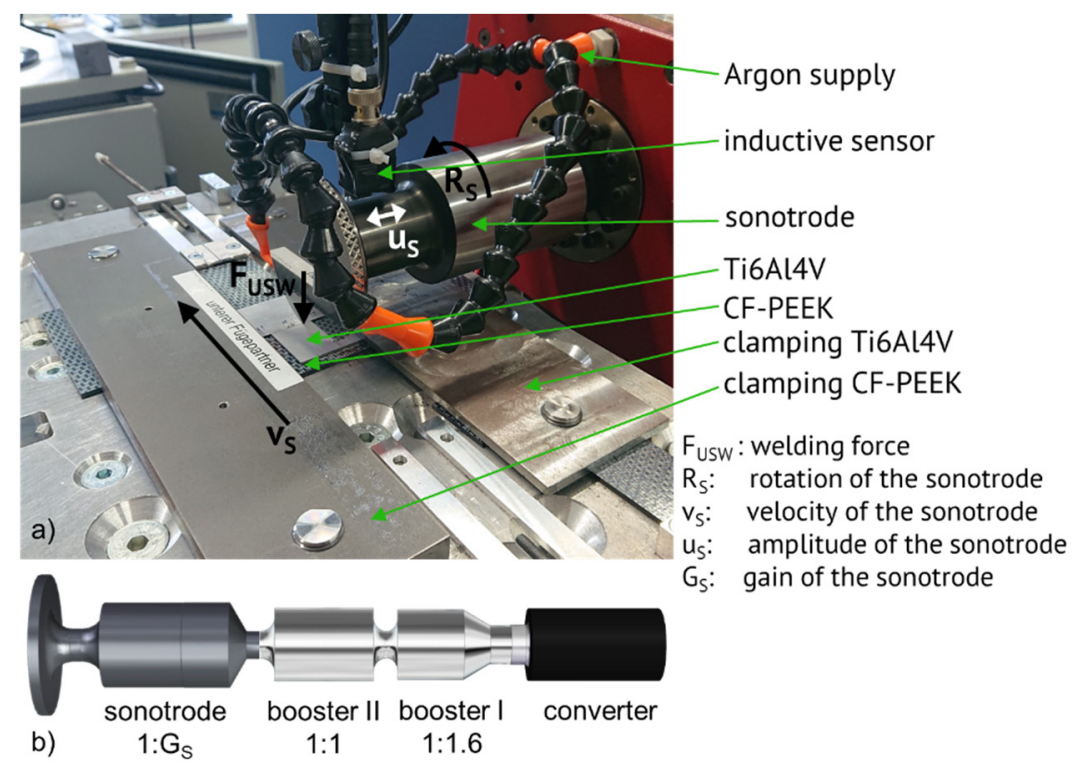

Figure 7. Experimental setup for planar ultrasonic welding of Ti6Al4V/CF-PEEK joints (a) welding area and (b) oscillation unit of the welding setup including acoustic transmission (1:G) of the incoming displacement amplitude.

\section{Sonotrode Development and Results}

\subsection{Materials Selection}

Currently, state-of-the-art sonotrode materials are aluminium or titanium alloys for ultrasonic polymer welding and tool steels or metal matrix composites for ultrasonic metal welding $[16,23]$. Sonotrodes made from materials specifically for ultrasonic welding of titanium are not commercially available to date and, therefore, the identification of suitable materials is a key aspect of this work. Since the strength and hardness of the sonotrode must be higher than that of the upper joining partner, sonotrodes made from aluminium or titanium were not considered in this work. Instead, sintered tool steel CPM RexM4 (ZAPP AG, Ratingen, Germany,), metal matrix composite Ferrotitanit WFN (DEW Specialty Steel GmbH \& Co. KG, Krefeld, Germany) and FeCoMo-alloy MC90 Intermet (voestalpine BOEHLER Edelstahl GmbH \& Co KG, Kapfenberg, Austria) were investigated as potential sonotrode materials. MC90 and CPM Rex M4 were considered for the first time for application in ultrasonic joining tools. The chemical compositions of all sonotrode materials investigated are listed in Tables $2-4$.

Table 2. Chemical composition of CPM RexM4 in wt\% [43].

\begin{tabular}{cccccccc}
\hline Fe & C & Mn & Si & Cr & V & Mo & W \\
\hline $79.3 \%$ & $1.4 \%$ & $0.3 \%$ & $0.3 \%$ & $4 \%$ & $4 \%$ & $5.2 \%$ & $5.5 \%$ \\
\hline
\end{tabular}

Table 3. Chemical composition of Ferrotitanit WFN in wt $\%$ [44].

\begin{tabular}{ccccc}
\hline & \multicolumn{2}{c}{ Steelmatrix (67\%) } & & $\begin{array}{c}\text { Ceramic Phase } \\
\mathbf{( 3 3 \% )}\end{array}$ \\
\hline $\mathrm{Fe}$ & $\mathrm{C}$ & $\mathrm{Cr}$ & $\mathrm{Mo}$ & $\mathrm{TiC}$ \\
\hline $82.75 \%$ & $0.75 \%$ & $13.5 \%$ & $3.0 \%$ & $100 \%$ \\
\hline
\end{tabular}

Table 4. Chemical composition of MC90 Intermet in wt $\%$ [42].

\begin{tabular}{ccccc}
\hline Fe & Si & Mn & Mo & Co \\
\hline $59.2 \%$ & $0.6 \%$ & $0.2 \%$ & $15 \%$ & $25 \%$ \\
\hline
\end{tabular}


Mechanical and acoustic properties as well as wear behaviour determine the performance of sonotrodes. Strength and hardness were considered mechanical properties. Therefore, Young's modulus, Poisson's ratio and mass density are needed to calculate dynamic behaviour. Relevant mechanical and physical properties of the materials are listed in Table 5 .

Table 5. Relevant material properties of promising sonotrode materials.

\begin{tabular}{cccc}
\hline & RexM4 [43] & WFN [44] & MC90 [42,45] \\
\hline $\begin{array}{c}\text { Hardness HRC } \\
\text { Young's Modulus in }\end{array}$ & 64 & 69 & 68 \\
GPa & 214 & 294 & 223 \\
$\begin{array}{c}\text { Mass density in } \\
\text { g/cm }\end{array}$ & 7.97 & 6.5 & 8.28 \\
Poisson's ratio & 0.3 & 0.24 & 0.2 \\
Machinability & + & -- & - \\
\hline
\end{tabular}

CPM RexM4 is a high-speed tool steel, typically used metal drilling. Compared to the commercially used sonotrode tool steel CPM 10V, the wear resistance of CPM RexM4 is lower, according to the manufacturer's data sheet [46]. However, Rex M4 was selected because of its high impact strength in comparison to other tool steels [43]. Ferrotitanit WFN is already used commercially as a sonotrode material. It offers a martensitic matrix reinforced by approximately $33 \mathrm{wt} \%$ titanium carbide. In comparison to tool steels used for sonotrodes, the wear resistance of Ferrotitanit WFN seems to be higher [45]. Relatively low mass density and high mechanical stiffness are also promising properties for applications as an oscillating tool. However, its machinability is challenging and the material is comparatively expensive [44]. MC90 Intermet is a FeCoMo-alloy developed particularly for the machining of titanium alloys [42]. Hardness and wear behaviour in contact with titanium, as well as mechanical strength, are promising properties as a candidate for robust sonotrodes.

Besides wear, fatigue strength is essential for the longevity of sonotrodes. During operation at $20 \mathrm{kHz}$ sonotrodes quickly reach $10^{9}$ cycles. Therefore, the very high cycle fatigue (VHCF) strength of sonotrode materials, beyond $10^{7}$ load cycles, is important to know. To estimate the maximum mechanical von Mises stress acceptable while oscillating, the fatigue behaviour of the sonotrode materials was investigated roughly. Despite different slopes of the S-N curves shown in Figure 8, the investigated sonotrode materials show a relatively similar fatigue strength for $2.5 \cdot 10^{9}$ load cycles, summarized in Table 6 .

Table 6. VHCF strength of sonotrode materials at $2.5 \times 10^{9}$ load cycles (ambient temperature).

\begin{tabular}{cccc}
\hline Materials & MC90 & WFN & RexM4 \\
\hline $\begin{array}{c}\text { Fatigue strength at } 2.5 \times 10^{9} \text { load } \\
\text { cycles in MPa }\end{array}$ & 430 & 380 & 413 \\
\hline
\end{tabular}

The microstructure has to be flawless and homogeneous to ensure a uniform deformation during oscillation to prevent stress peaks. Additionally, fine grains and small reinforcing phases are beneficial for the fatigue behaviour of sonotrode materials $[47,48]$. The microstructures of the investigated materials are shown in Figure 9. The dimensions of primary phase, grains and reinforcing secondary phases are given in Table 7. The RexM4 and MC90 specimens had similar grain and phase sizes, whereas the grain size of WFN was significantly smaller. The amount and size of the reinforcing titanium carbides in WFN was much larger compared to the carbides $\mathrm{VC}, \mathrm{Mo}_{2} \mathrm{C}$ and $\mathrm{WC}$ in RexM4 and the intermetallic FeCoMo $\mu$-phase in MC90. Additionally, TiC occurred in clusters with areas of 30-200 $\mu \mathrm{m}$ or large TiC particles up to $30 \mu \mathrm{m}$ in diameter. WFN was therefore considered to be more prone to fatigue damage than RexM4 and MC90, as the particle clusters are stiffer regions that may cause harmful stress concentrations [49], correlating to the VHCF 
behaviour observed in this work. Figure 9 shows the reinforcing phases determined by light optical microscopy (a) and the grain structure visualised by electron back scatter diffraction (EBSD) (b) of RexM4 (I), MC90 (II) and WFN (III). The colours used in the EBSD micrographs indicate the grain orientation, but, in this case, the colours were used only for improved visibility of the grain structure. From the micrographs, the dimensions of grains and reinforcing phases were measured using the line-intercept method. The contents of the reinforcing phases were determined by digital image analysis using the proportionate area of each phase. All materials showed a fine microstructure and a homogeneously distributed grain size and morphology leading to isotropic materials properties of the sonotrodes.

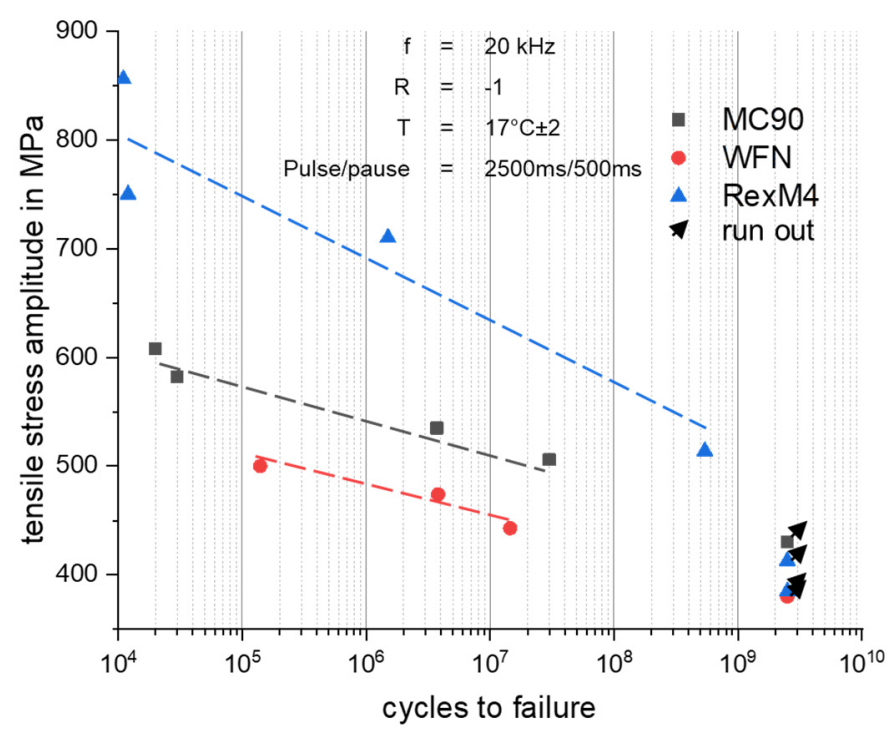

Figure 8. Summarized results of ultrasonic fatigue experiments for all investigated sonotrode materials.

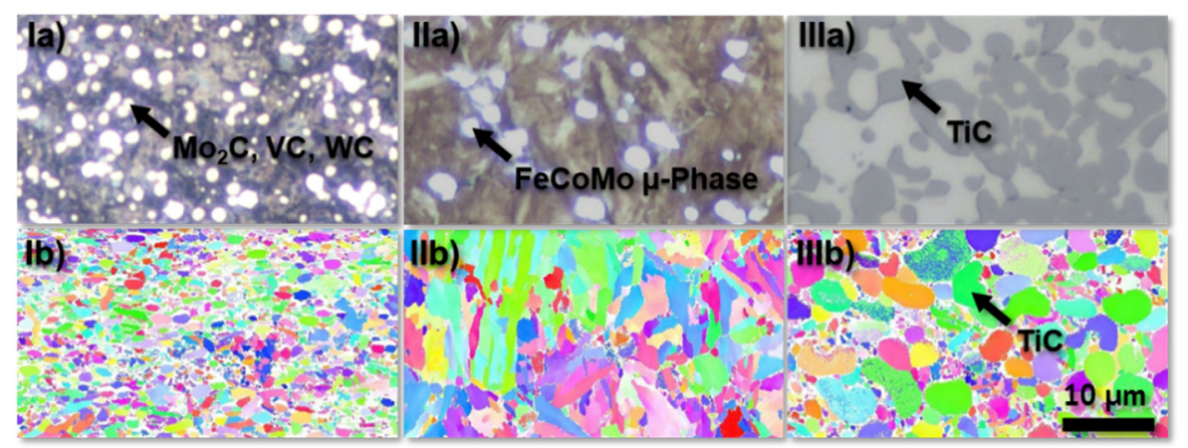

Figure 9. Reinforcing phases determined by light optical microscopy (a) and grain structure determined by electron back scatter diffraction (b) of RexM4 (I), MC90 (II) and WFN (III).

Table 7. Observed grain and particle size of selected sonotrode materials.

\begin{tabular}{cccc}
\hline & RexM4 & WFN & MC90 \\
\hline Grain size in $\mu \mathrm{m}$ & $1-3$ & $0.3-3$ & $3-6$ \\
$\begin{array}{c}\text { Size of reinforcing } \\
\text { phase in } \mu \mathrm{m}\end{array}$ & $1-2$ & $5-8$ & $1-3$ \\
$\begin{array}{c}\text { Content of reinforcing } \\
\text { phase in area\% }\end{array}$ & 20 & 33 & 6 \\
\hline
\end{tabular}

\subsection{Design of the Sonotrode Geometry}

As described in Section 2, the sonotrode dimensions were adjusted to comply with the operational frequency of the generator as well as the applied operational mode and 
to isolate the operational mode from other modes to avoid undesired modal interactions by using FE model I (see Figure 3). FE model II (see Figure 4) representing only the front part of the sonotrode, was used to determine critical mechanical stresses. Both approaches were necessary to fulfil the requirements of a longitudinal mode at $20 \mathrm{kHz}$, isolated by $1000 \mathrm{~Hz}$ from other modes, and maximum mechanical stresses of up to $350 \mathrm{MPa}$ at a $50-\mu \mathrm{m}$ deflection of the sonotrode tip.

\subsubsection{Modal Frequency and Modal Shape of the Operational Mode}

The sonotrodes developed for this research were designed for continuous ultrasonic welding at a frequency of $20 \mathrm{kHz}$. Based on the frequencies calculated using the FE model I, the preliminary geometry was adjusted to a target frequency of $20 \mathrm{kHz}$ of the required longitudinal operational mode and a separation to all other vibrational modes of at least $\pm 1000 \mathrm{~Hz}$. The geometry of rotary ultrasonic sonotrodes is relatively complex. The more complex the geometry, the closer the distance between the modes, and the more modes appear due to a larger amount of mass sections compared to a single mass oscillator [25]. The sonotrode geometry applied in this work can be separated into sections which are separated by every change of diameter. The impact of each section on the change of the modal frequency of the longitudinal mode was examined using FE model I by modifying of the respective dimension and observing the resulting change in modal frequency and mechanical stresses. A model of the deformation of a sonotrode during the longitudinal oscillation is given in Figure 10.

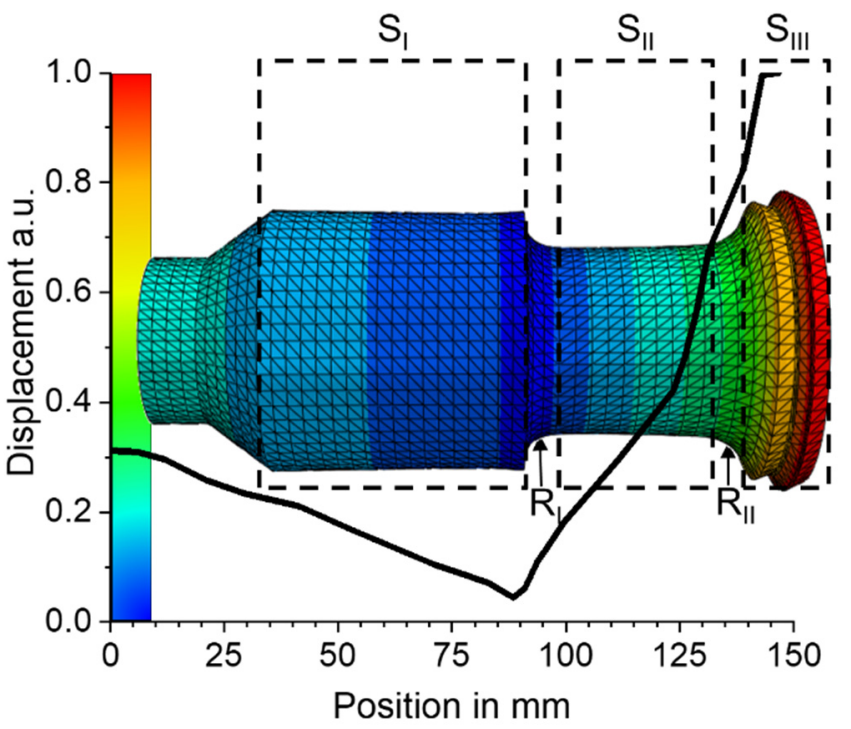

Figure 10. Model of calculated normalised displacement as function of position in rotational symmetric ultrasonic welding sonotrodes.

The model shows the relative deformation behaviour as a function of the position, supported by an additional colour code. The three most important sections $\mathrm{S}_{\mathrm{I}-\mathrm{III}}$, and two radii $R_{I}, R_{I I}$ are indicated. The frequency of the longitudinal operating mode is mainly influenced by the length of $S_{I}, S_{I I}$ and $S_{I I I}$, as well as the diameter ratio between $S_{I}$ and $S_{I I}$. The radii $R_{I}$ and $R_{I I}$ have a smaller influence on the target frequency. The acoustic transmission is primarily determined by the diameter ratio $S_{I} / S_{I I}$. To gain the initial displacement amplitude, $S_{I I}$ has to be smaller than $S_{I}$. The larger the radii, the lower is the resulting gain. Note that, the impact of radii on stress is greater than on transmission, especially for $R_{\mathrm{II}}$.

\subsubsection{Mechanical Stresses Relating to Displacement Amplitude at the Sonotrode Tip}

A maximum von Mises stress of $350 \mathrm{MPa}$ was assumed to be a suitable limit for applications beyond $10^{9}$ loading cycles, according to the VHCF tests (see Figure 8) and 
supposing that the temperature does not significantly increase beyond the contact area between sonotrode and titanium, due to the process speed and cooling by Argon flow. The occurring stresses for a given sonotrode tip displacement mainly depend on Young's modulus and the sonotrode geometry. However, comparing different materials for sonotrodes is difficult as the final geometry meeting the abovementioned requirements for acoustic behaviour depend on the material's properties. To compare the stress distribution of the materials $S_{\text {III }}$ was kept constant for each sonotrode concept. In contrast to RexM4 and MC90, WFN has a much higher stiffness (see Table 5), which caused different deformation behaviour and stress distribution. A comparison of the von Mises stress distributions in the WFN and MC90 sonotrodes is presented in Figure 11. RexM4 (E=214 GPa) and MC90 $(E=223 \mathrm{GPa})$ have relatively similar elastic mechanical properties. Hence, the calculated von Mises stress distributions were almost identical in these materials, while higher stresses occurred in the WFN sonotrode tip because of its significantly higher young's modulus $(\mathrm{E}=294 \mathrm{GPa})$ that results in larger stresses at a given deformation. The more uniform deformation of the sonotrode along the oscillation direction further increased the occurring stresses. Moreover, a large difference between the diameters of $\mathrm{S}_{\mathrm{II}}$ and $\mathrm{S}_{\mathrm{III}}$ was favourable with respect to improved acoustic transmission. As seen in Figure 8, the larger diameter in $S_{\text {III }}$ for MC90 $(80 \mathrm{~mm})$ caused a more homogeneous distribution of stress despite the increased bending of the sonotrode tip.

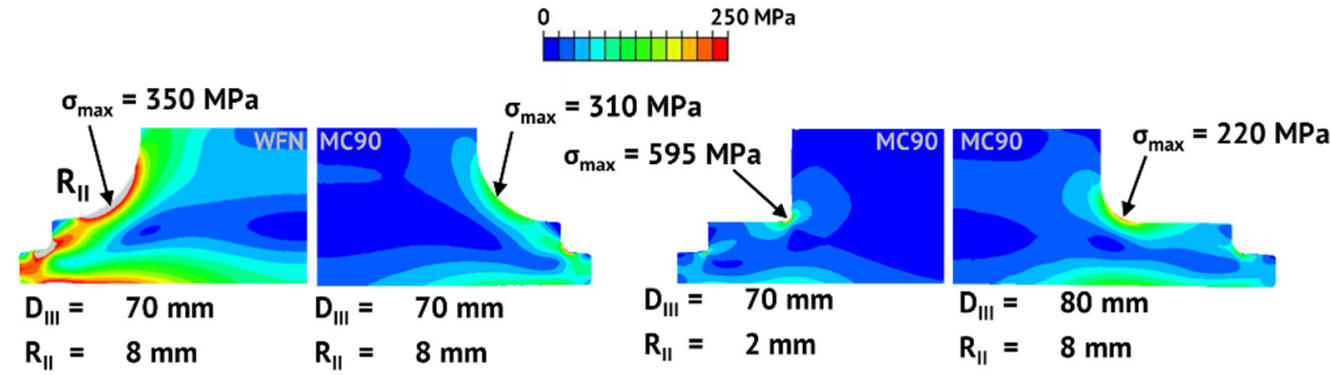

Figure 11. Von Mises stress distribution in the sonotrode, comparing the impact of elastic properties of WFN and MC90 and of the shape considering $\mathrm{R}_{\mathrm{II}}$ and $\mathrm{D}_{\mathrm{III}}$ of MC90 sonotrodes.

The design of the sonotrode tip topography is a further geometric parameter that determines the energy input into the welding zone and the longevity of the tool, limited by wear [40]. The influence of the sonotrode tip topography on the stress distribution (see Figure 5) was evaluated by FEM simulations as well as by the achieved joint strength. In welding experiments MC90 sonotrodes with a knurled and a pyramidal sonotrode tip topography were used as shown in Figure 12. The qualitative von Mises stress distribution that occurs due to the relative motion of the sonotrode in contact with the joining partners, i.e., Ti6Al4V, is shown in Figure 12. The averaged von Mises stress occurring with a knurled topography is three times higher compared to a pyramidal structure. A pyramidal topography allows a force distribution over a $\sqrt{2}$ larger area. Hence, the resulting stress in the joining partners and in the sonotrode tip is lower leading to the expectation that a pyramidal sonotrode tip topography is more effective than a knurled topography. 
(a)
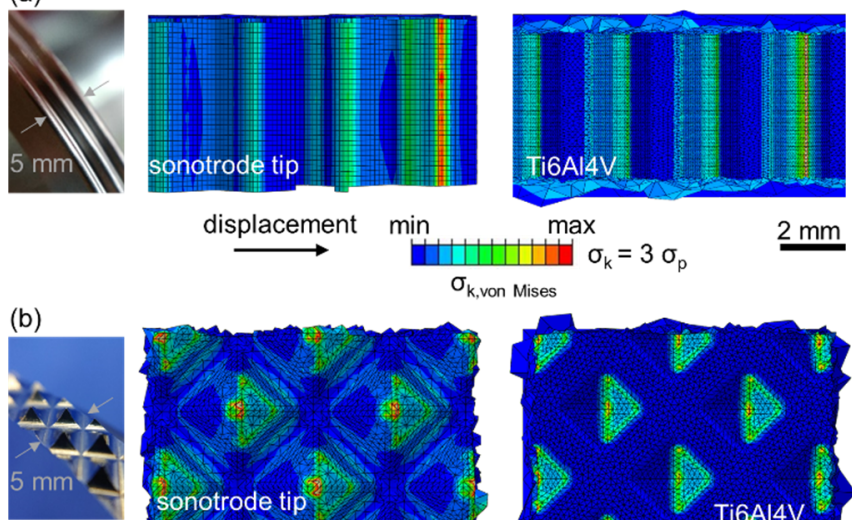

displacement $\min$ $\max$

$2 \mathrm{~mm}$

$\sigma_{\mathrm{k}, \text { von Mises }}$

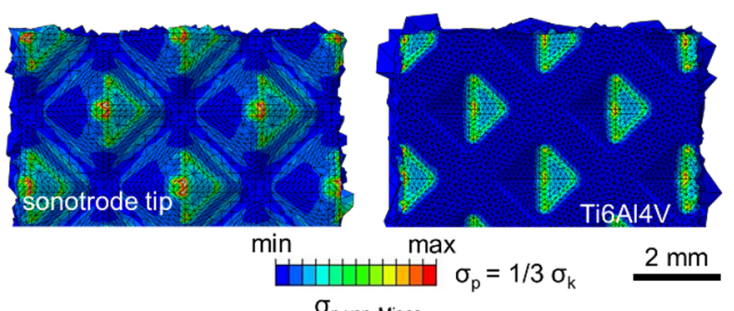

$\sigma_{p, \text { von Mises }}$

Figure 12. Qualitative von Mises stress distribution in the sonotrode tip and contacting Ti6Al4V due to the displacement caused by relative motion depending on the sonotrode tip topography (a) knurled and (b) pyramidal sonotrode tip topography.

\subsection{Modal Analysis}

It was important to investigate the acoustic behaviour of all the sonotrodes after manufacturing to verify their functionality, in particular, the amplitude and frequency of the operational mode and to prelude undesirable modal interaction. Theoretical modal analysis was performed by FEM during the design process to determine the modal shape and modal frequencies. The experimental modal analyses are summarised in Figure 13 for the final designs of the RexM4, WFN and MC90 sonotrodes. No modal interaction occurred as the measured shape corresponded to the calculated longitudinal mode. Considering the RexM4 sonotrode, the neighbouring flexural mode was slightly less than $1000 \mathrm{~Hz}$ apart from the operating mode. Nevertheless, the modes were sufficiently isolated, because the modal shape was homogeneous and did not show any interaction. The differences between the modal shapes of MC90 and both other materials RexM4 and WFN are caused by the higher transmission ratio and hence higher resulting displacement amplitudes at the sonotrode tip achieved in the measuring setup for modal analysis (see Figure 6).

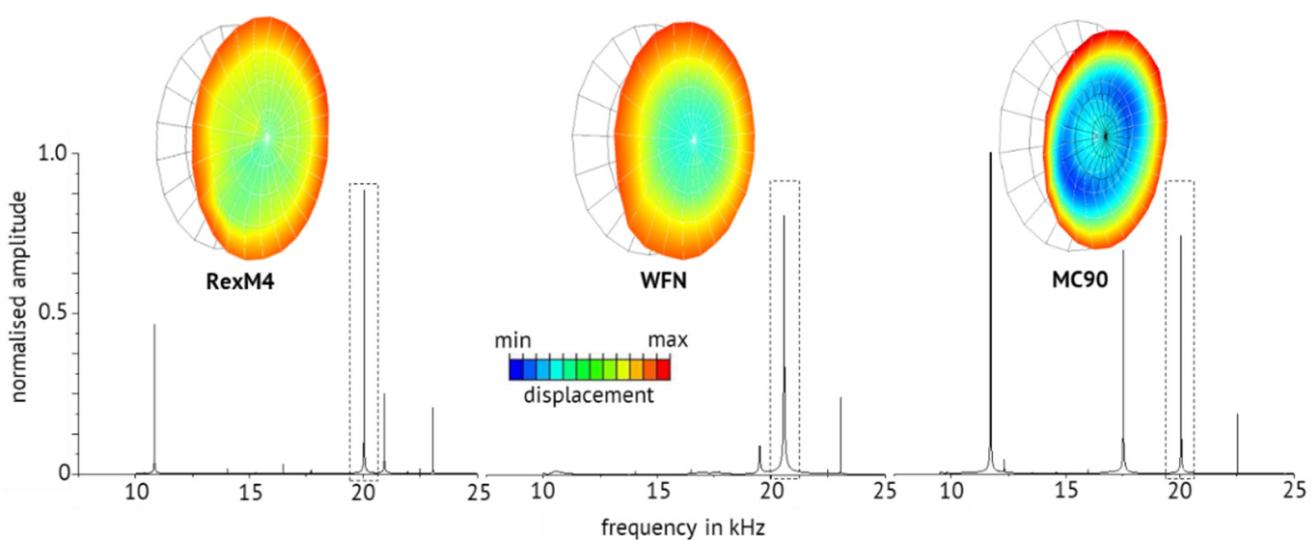

Figure 13. Modal analyses of RexM4 (S1), WFN (S2) and MC90 (S3) sonotrodes by 3D Laser Doppler vibrometry including the measured modal shape of the operational mode at $20 \mathrm{kHz}$ (Link To Supplementary Materials).

The characteristics of the RexM4, WFN and MC90 sonotrodes are listed in Table 8, comparing theoretical and experimental modal analyses. The findings showed that the MC90 and RexM4 operational modes were very close to $20 \mathrm{kHz}$. Despite the fact that the 
operational mode of the WFN sonotrode differed by $230 \mathrm{~Hz}$ from $20 \mathrm{kHz}$, all the sonotrodes could be operated by the available welding system (Branson Ultraseam 20, Danbury, CT, USA), which allows adjustment of its operational frequency by $\pm 350 \mathrm{~Hz}$.

Table 8. Acoustic characteristics of the RexM4, WFN and MC90 sonotrodes measured by Laser Doppler vibrometry.

\begin{tabular}{ccccc}
\hline & & Modal Frequency in $\mathbf{H z}$ & & $\begin{array}{c}\text { Transmission of } \\
\text { the Sonotrode }\end{array}$ \\
\hline RexM4 & $\mathbf{f}_{\mathbf{i}}$ Initial & $\mathbf{f}_{\mathbf{a}}$ Annealed & $\mathbf{f}_{\mathbf{i}}-\mathbf{f}_{\mathbf{a}}$ & $\mathbf{1 : G}$ \\
WFN & 20,540 & 20,035 & 505 & $1: 2.81$ \\
MC90 & 20,500 & 20,230 & 270 & $1: 2.67$ \\
& 20,700 & 20,030 & 670 & $1: 3.13$ \\
\hline
\end{tabular}

Thermal treatment has a remarkable impact on the eigenfrequencies of the sonotrodes complicating the calculation and design by theoretical modal analysis. The eigenfrequencies of RexM4 and MC90 decreased by $505 \mathrm{~Hz}$ and $670 \mathrm{~Hz}$, but only by $270 \mathrm{~Hz}$ for WFN, that includes $33 \mathrm{wt} \%$ of ceramic phase. As the ceramic phase stays unaffected by annealing, the smaller change of the eigenfrequency is reasonable. However, the change of eigenfrequencies for all materials considered for sonotrodes can be included in the design process to reliable calculate the eigenfrequencies. The acoustic transmission of the sonotrode $1: G$ describes the ratio between the incoming and the resulting amplitude, gaining $(G>1)$ or attenuating $(G<1)$ the displacement amplitude, determined by sonotrode shape and acoustic properties of the materials. The abovementioned minimum sonotrode transmission of 1:2.6 to achieve the requested amplitude of $50 \mu \mathrm{m}$ for the welding setup used in this work is fulfilled by all sonotrodes. The noticeable differences between the transmissions of each sonotrode are primarily caused by the materials properties such as mechanical damping, since the geometries are very similar.

\subsection{Sonotrode Suitability for Ultrasonic Welding of Ti6Al4V to CF-PEEK}

The performance of each sonotrode in the actual ultrasonic welding process was investigated considering the tensile shear strength of the Ti6Al4V/CFRP-joints, shown in Figure 14. Preliminary tests already revealed, that sonotrodes made from RexM4 were not capable to weld with a displacement amplitude of $50 \mu \mathrm{m}$. Therefore, the joints chosen for comparison of the sonotrodes in this work were ultrasonically welded with a displacement amplitude of $30 \mu \mathrm{m}$, a welding force of $120 \mathrm{~N}$ and a welding velocity of $2.5 \mathrm{~mm} / \mathrm{s}$ without shielding gas. The colour of the welding seam in Figure 14 indicates temperatures up to $700{ }^{\circ} \mathrm{C}$ at the contact zone between sonotrode and metal surface according to the temperature-colour bar that has been determined by annealing Ti6Al4V sheets in ambient air. The relative tensile shear force of the samples welded for a comparison of the sonotrodes is listed in Figure 14. The strength of the hybrid joints welded with a RexM4 sonotrode was significantly lower compared to joints welded using the WFN sonotrode and MC90 sonotrode. 


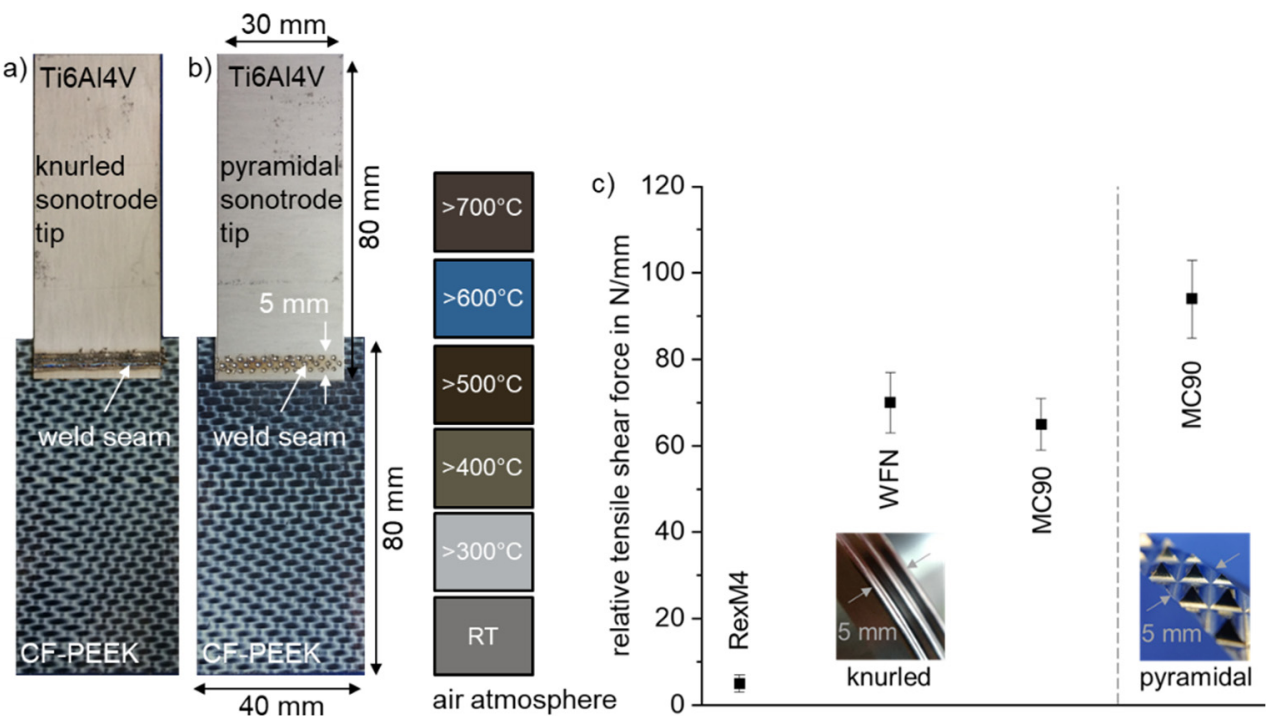

Figure 14. Ultrasonically welded Ti6Al4V/CF-PEEK joints (a) by knurled sonotrode tip and (b) by pyramidal sonotrode tip and (c) the resulting ultimate relative tensile shear force.

Apparently, a displacement amplitude of $30 \mu \mathrm{m}$ is sufficiently high to join Ti6Al4V to CF-PEEK, but the joint strengths are relatively low and the joints failed interfacial. However, experiments regarding the development of ultrasonic welding processes of Ti6Al4V/CFPEEK-joints that are not part of this work showed, that displacement amplitudes up to $48 \mu \mathrm{m}$ lead to joint strength up to a relative tensile shear force of $390 \mathrm{~N} / \mathrm{mm}(97.5 \mathrm{MPa})$ for Ti6Al4V/CF-PEEK joints [14]. The highest relative tensile shear force of $94 \mathrm{~N} / \mathrm{mm}$ $(23.5 \mathrm{MPa})$ was achieved for an MC90 sonotrode with a pyramidal sonotrode tip topography corresponding to the calculations and hypotheses outlined in Figure 12. Similar hybrid joints of aluminium alloy, glass fibre ply and CF-PEEK (AA5024/(GF)-CF-PEEK) joint by torsional ultrasonic welding showed a strength up to $83 \mathrm{MPa}$ [5]. In contrast to the interfacial failure of the joints investigated in scope of the sonotrode development, high strength show an interlocking between fibres and metal that leads to failure in the upper layers of the fibre reinforced polymers $[5,14]$.

An exceptionally low strength of the joints produced with the RexM4 sonotrodes is attributed to the very pronounced wear of this material during the ultrasonic welding of titanium. Abrasion of the RexM4 sonotrode caused the welding energy to partially dissipate, resulting in reduced wedding energy transmitted into the joining zone. After a cumulated welding seam length of $1 \mathrm{~m}$, the height of the RexM4 sonotrode tip profile was reduced by approximately 30\%, whereas the sonotrode tips of WFN and MC90 did not show significant abrasion. The welding quality and wear behaviour of the WFN sonotrode and MC90 sonotrode were similar. However, the WFN sonotrode failed due to fatigue after welding of 1-4 m cumulated weld seam lengths ( 1-3 $\times 10^{7}$ cycles). The cause of fatigue failure can be seen in the fractured surface of the WFN sonotrode, which revealed the presence of $\mathrm{TiC}$ clusters with diameters up to $30 \mu \mathrm{m}$. In Figure 15a, the darker areas are $\mathrm{TiC}$ particles, identified by electron dispersive X-ray spectroscopy (EDS). The clusters appeared randomly in the WFN sonotrode and possibly caused fatigue failure due do enhanced mechanical stress at the TiC particles. The fracture surface of a WFN VHCF sample that failed in the same load cycle range as the sonotrodes also shows TiC clusters that may have caused the failure in Figure 15b. 

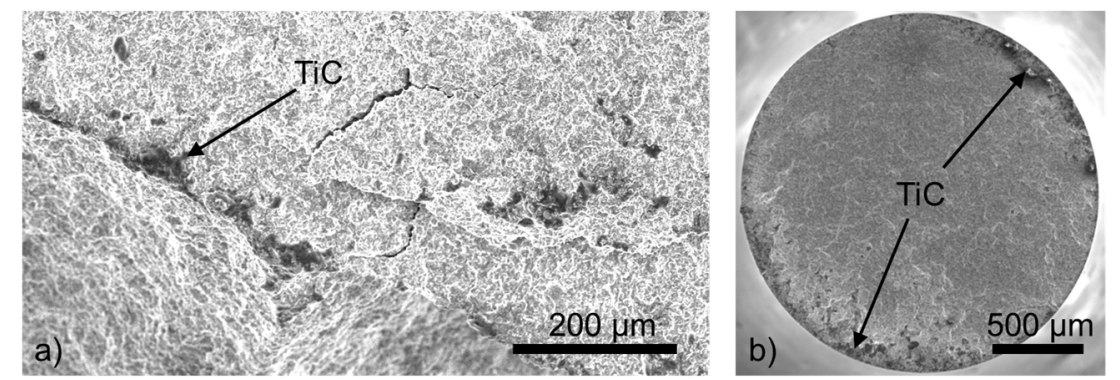

Figure 15. Fracture surface (SEM) of (a) WFN sonotrode after fatigue failure showing TiC particle clusters (darker areas) and (b) WFN VHCF sample that failed after $1.5 \times 10^{7}$ cycles.

The VHCF behaviour was investigated at ambient temperature, but annealing colours on the welding samples indicate local temperatures up to $700{ }^{\circ} \mathrm{C}$. However, the WFN sonotrode failed at Radius II (see Figure 10) that remained close to ambient temperature $\left(20-25^{\circ} \mathrm{C}\right)$ according to IR temperature measurements during the welding process. Large TiC particle clusters were identified as crack initiation sites indicating an insufficient homogeneity of the material that leads to lower VHCF strength. Additionally, the state of stress during welding is complex, possibly resulting in critically high total stress.

In comparison to commercially applied sonotrode materials, the performance of MC90 is outstanding. Displacement amplitudes above $48 \mu \mathrm{m}$ were applied for more than $10^{8}$ loading cycles during the welding of Ti6Al4V to CFRP without failure and without pronounced wear [14]. The sonotrode was used for a cumulative welding seam length of $40 \mathrm{~m}$ corresponding to approximately $3 \times 10^{8}$ loading cycles. A continuous decrease in joint quality over tool's longevity was not detected during the study.

\section{Summary}

Three different sonotrode materials were considered for the continuous ultrasonic seam welding of titanium/CFRP joints: CPM RexM4, Ferrotitanit WFN and MC90 Intermet, each featuring different elastic properties, hardnesses, wear behaviour, and microstructural homogeneities. Using these materials, rotationally symmetric sonotrodes were designed via FEM simulation to achieve displacement amplitudes of up to $50 \mu \mathrm{m}$ and simultaneously keep the resulting von Mises stress amplitudes lower than $350 \mathrm{MPa}$ in order to prevent early fatigue failure according to the VHCF investigations performed. From a geometric point of view, the diameter ratios and lengths of the sonotrode segments (see Figure 7) determined the acoustic transmission as well as the resulting stresses. The stress amplitudes could be kept in the abovementioned limits by choosing appropriate transition radii between the sonotrode segments.

The acoustic properties of sonotrodes designed in this way were measured by modal analysis using Laser Doppler vibrometry to determine modal shapes and frequencies. While modal analysis was primarily used to verify the geometric design, welding experiments were performed to examine the performance of the sonotrodes for the ultrasonic seam welding of Ti6Al4V (upper joining partner) to CFRP. Considering the ultimate tensile shear force in relation to the welding seam length, WFN and MC90 performed similarly well, while the strength of the joints welded by a RexM4 sonotrode was insufficiently low. The high abrasive wear on RexM4, resulting in poor transmission of the welding energy into the welding zone, was considered the main reason for this poor welding performance. A pyramidal sonotrode tip topography showed a promisingly lower stress level in comparison to a knurled topography in the FE model and lead to the highest joint strength in the welding experiments. Notably, all the WFN sonotrodes failed due to fatigue in the sonotrode tip after reaching cumulative weld seam lengths between $1 \mathrm{~m}$ and $4 \mathrm{~m}$, indicating a lower VHCF strength then the assumed limit of $350 \mathrm{MPa}$ for the sonotrode design.

Comparing all the sonotrode materials examined, MC90 was found to be objectively the best choice for robust sonotrodes used in continuous ultrasonic welding of Ti6Al4V to CFRP. Despite the fatigue failure of WFN, its wear behaviour as well as the achieved 
joint quality were promising and hence, WFN is possibly suitable in combination with a different sonotrode design.

Supplementary Materials: The following are available online at https://www.mdpi.com/article/ 10.3390/jmmp5020061/s1, Figures S1-S3 in addition to Figure 13. Modal analyses of RexM4, WFN and MC90 sonotrodes by 3D Laser Doppler vibrometry including the measured modal shape of the operational mode at $20 \mathrm{kHz}$ (Link to Supplementary Materials https:/ / doi.org/10.5281/zenodo.4731 150). Figure S1: RexM4 sonotrode at $20 \mathrm{kHz}$, Figure S2: WFN sonotrode at $20 \mathrm{kHz}, \mathrm{MC} 90$ sonotrode at $20 \mathrm{kHz}$.

Author Contributions: Conceptualization, M.L., T.B. and F.B.; methodology, M.L.; simulations, M.L. and Y.Y.; writing original draft, M.L.; review and editing T.B. and F.B.; funding acquisition, F.B. All authors have read and agreed to the published version of the manuscript.

Funding: This research was funded by German Federal Ministry for Economic Affairs and Energy (BMWi), HydI CReMA, 20Y1506F. The APC was funded by DFG Funding Programme Open Access Publishing.

Institutional Review Board Statement: Not applicable.

Informed Consent Statement: Not applicable.

Data Availability Statement: The data presented in this study are available on request from the corresponding author.

Acknowledgments: The authors thank the German Federal Ministry for Economic Affairs and Energy (BMWi) for financial support within the federal aviation research programme (LuFo) V, Hydraulic System Innovations for Cost Reduced Modular Applications (HydI CReMA, 20Y1506F). Gratitudes are also expressed to Ulrich Vogler and Stefan Zendler (Herrmann Ultrasonics GmbH, Karlsbad, Germany) for the opportunity to use their full field Laser Doppler vibrometer for modal analysis. Sincere thanks also go to our colleagues Hendrik Rüters for assistance in CAD work, Matasha Mazis for proof reading and Benedikt Engel for fruitful discussions.

Conflicts of Interest: The authors declare no conflict of interest.

\section{References}

1. Amancio-Filho, S.T.; Blaga, L.-A. Joining of Polymer-Metal Hybrid Structures; John Wiley \& Sons, Inc.: Hoboken, NJ, USA, 2018; ISBN 9781119429807.

2. Lambiase, F.; Balle, F.; Blaga, L.-A.; Liu, F.; Amancio-Filho, S.T. Friction-based processes for hybrid multi-material joining. Compos. Struct. 2021, 266, 113828. [CrossRef]

3. Villegas, I.F. Strength development versus process data in ultrasonic welding of thermoplastic composites with flat energy directors and its application to the definition of optimum processing parameters. Compos. Part A Appl. Sci. Manuf. 2014, 65, 27-37. [CrossRef]

4. Harman, G.; Albers, J. The Ultrasonic Welding Mechanism as Applied to Aluminum-and Gold-Wire Bonding in Microelectronics. IEEE Trans. Parts Hybrids Packag. 1977, 13, 406-412. [CrossRef]

5. Staab, F.; Balle, F. Ultrasonic torsion welding of ageing-resistant Al/CFRP joints: Properties, microstructure and joint formation. Ultrasonics 2019, 93, 139-144. [CrossRef]

6. Balle, F.; Wagner, G.; Eifler, D. Ultrasonic Metal Welding of Aluminium Sheets to Carbon Fibre Reinforced Thermoplastic Composites. Adv. Eng. Mater. 2009, 11, 35-39. [CrossRef]

7. Balle, F; Eifler, D. Statistical test planning for ultrasonic welding of dissimilar materials using the example of aluminum-carbon fiber reinforced polymers (CFRP) joints. Mat. Wiss. U. Werkst. 2012, 43, 286-292. [CrossRef]

8. Magin, J.; Balle, F. Solid state joining of aluminum, titanium and their hybrids by ultrasonic torsion welding. Mat. Wiss. Werkst. 2014, 45, 1072-1083. [CrossRef]

9. Fujii, H.T.; Goto, Y.; Sato, Y.S.; Kokawa, H. Microstructure and lap shear strength of the weld interface in ultrasonic welding of Al alloy to stainless steel. Scr. Mater. 2016, 116, 135-138. [CrossRef]

10. Shimizu, S.; Fujii, H.T.; Sato, Y.S.; Kokawa, H.; Sriraman, M.R.; Babu, S.S. Mechanism of weld formation during very-high-power ultrasonic additive manufacturing of $\mathrm{Al}$ alloy 6061. Acta Mater. 2014, 74, 234-243. [CrossRef]

11. Watanabe, T.; Sakuyama, H.; Yanagisawa, A. Ultrasonic welding between mild steel sheet and Al-Mg alloy sheet. J. Mater. Process. Technol. 2009, 209, 5475-5480. [CrossRef]

12. Patel, V.K.; Bhole, S.D.; Chen, D.L. Ultrasonic spot welded AZ31 magnesium alloy: Microstructure, texture, and lap shear strength. Mater. Sci. Eng. A 2013, 569, 78-85. [CrossRef] 
13. Panteli, A.; Robson, J.D.; Brough, I.; Prangnell, P.B. The effect of high strain rate deformation on intermetallic reaction during ultrasonic welding aluminium to magnesium. Mater. Sci. Eng. A 2012, 556, 31-42. [CrossRef]

14. Liesegang, M.; Arweiler, S.; Beck, T.; Balle, F. Orbital Ultrasonic Welding of Ti-Fittings to CFRP-Tubes. J. Manuf. Mater. Process. 2021, 5, 30. [CrossRef]

15. Zhang, C.; Robson, J.D.; Haigh, S.J.; Prangnell, P.B. Interfacial Segregation of Alloying Elements During Dissimilar Ultrasonic Welding of AA6111 Aluminum and Ti6Al4V Titanium. Met. Mat. Trans. A 2019, 50, 5143-5152. [CrossRef]

16. Neppiras, E.A. Very high energy ultrasonics. Br. J. Appl. Phys. 1960, 11, 143-150. [CrossRef]

17. Amin, S.G.; Ahmed, M.H.M.; Youssef, H.A. Computer-aided design of acoustic horns for ultrasonic machining using finiteelement analysis. J. Mater. Process. Technol. 1995, 55, 254-260. [CrossRef]

18. Derks, P.P. The Design of Ultrasonic Resonators with Wide Output Cross-Sections. Ph.D. Thesis, Technische Hogeschool Eindhoven, Eindhoven, The Netherlands, 1984. [CrossRef]

19. Stănăşel, I.; Buidoş, T.; Blaga, F. Design and FEM simulation of ultrasonic welding horn. Rom. Assoc. Nonconv. Technol. 2014, 18, 51-55.

20. Nanu, A.S. Study on ultrasonic stepped horn geometry design and FEM simulation. Nonconv. Technol. Rev. 2011, 4/2011, 25-30.

21. Roopa Rani, M.; Rudramoorthy, R. Computational modeling and experimental studies of the dynamic performance of ultrasonic horn profiles used in plastic welding. Ultrasonics 2013, 53, 763-772. [CrossRef]

22. Lin, S.; Guo, H.; Xu, J. Actively adjustable step-type ultrasonic horns in longitudinal vibration. J. Sound Vib. 2018, 419, 367-379. [CrossRef]

23. Emmer, Š.; Kováčik, J.; Baksa, P. Effect of microstructure on the sonotrode properties of tool materials Ferro-titanit ${ }^{\circledR}$ WFN and steel CPM 10V ${ }^{\circledR}$. Met. Mater. 2016, 53, 423-428. [CrossRef]

24. Emmer, Š.; Kováčik, J.; Mrkvová, S. Materials for sonotrode tools. Sci. Proc. Fac. Mech. Eng. STU Bratisl. 2013, 21, 503. [CrossRef]

25. Thorby, D. Structural Dynamics and Vibration in Practice: An Engineering Handbook; Butterworth-Heinemann: Oxford, UK, 2008; ISBN 9780080557151.

26. Lucas, M.; Cardoni, A.; Lim, F.C.N.; Cartmell, M.P.; McGeough, J.A. Effects of Modal Interactions on Vibration Performance in Ultrasonic Cutting. CIRP Ann. 2003, 52, 193-196. [CrossRef]

27. Lucas, M.; Petzing, J.N.; Cardoni, A.; Smith, L.J.; McGeough, J.A. Design and Characterisation of Ultrasonic Cutting Tools. CIRP Ann. 2001, 50, 149-152. [CrossRef]

28. Cardoni, A.; Lucas, M. Enhanced vibration performance of ultrasonic block horns. Ultrasonics 2002, 40, 365-369. [CrossRef]

29. Cardoni, A.; Lucas, M.; Cartmell, M.; Lim, F. A novel multiple blade ultrasonic cutting device. Ultrasonics 2004, 42, 69-74. [CrossRef]

30. Budairi, H.D. Design and Analysis of Ultrasonic Horns Operating in Longitudinal and Torsional Vibration. PhD Thesis, University of Glasgow, Glasgow, UK, , 2012. Unique ID: Glathesis:2012-3851.

31. Brouet, F.; Twiefel, J.; Wallaschek, J. Modal interaction in ultrasonic welding block sonotrodes induced by the mistuning of the material properties. J. Sound Vib. 2016, 381, 1-13. [CrossRef]

32. Harkness, P.; Lucas, M.; Cardoni, A. Coupling and degenerating modes in longitudinal-torsional step horns. Ultrasonics 2012, 52, 980-988. [CrossRef]

33. Tsujino, J.; Ueoka, T.; Kashino, T.; Sugahara, F. Transverse and torsional complex vibration systems for ultrasonic seam welding of metal plates. Ultrasonics 2000, 38, 67-71. [CrossRef]

34. Tsujino, J.; Harada, Y.; Ihara, S.; Kasahara, K.; Shimizu, M.; Ueoka, T. Configurations of high-frequency ultrasonics complex vibration systems for packaging in microelectronics. Ultrasonics 2004, 42, 125-129. [CrossRef]

35. Tsujino, J.; Ueoka, T. Ultrasonic Seam Welding System Using a Complex Vibration Circular Disk in Transverse and Torsional Vibrations. Jpn. J. Appl. Phys. 1999, 38, 3307-3311. [CrossRef]

36. Smaga, M.; Boemke, A.; Daniel, T.; Skorupski, R.; Sorich, A.; Beck, T. Fatigue Behavior of Metastable Austenitic Stainless Steels in LCF, HCF and VHCF Regimes at Ambient and Elevated Temperatures. Metals 2019, 9, 704. [CrossRef]

37. Beck, T.; Kovacs, S.A.; Ritz, F. VHCF Behavior and Word Hardening of a Ferritic-Martensitic Steel at High Mean Stresses. Key Eng. Mater. 2015, 664, 246-254. [CrossRef]

38. Nad, M. Ultrasonic horn design for ultrasonic machining technologies. Appl. Comput. Mech. 2010, 4, 79-88.

39. Chen, K.; Zhang, Y. Mechanical analysis of ultrasonic welding considering knurl pattern of sonotrode tip. Mater. Des. 2015, 87, 393-404. [CrossRef]

40. Qu, J.; Blau, P.J.; Watkins, T.R.; Cavin, O.B.; Kulkarni, N.S. Friction and wear of titanium alloys sliding against metal, polymer, and ceramic counterfaces. Wear 2005, 258, 1348-1356. [CrossRef]

41. CES Edupack; Granta Design: Cambridge, UK, 2018.

42. MC90 Intermet: Datasheet; Böhler voestalpine: Kapfenberg, Austria, 2019.

43. CPM RexM4: Datasheet; Zapp Materials Engineering GmbH: Ratingen, Germany, 2016.

44. Ferrotitanit: Datasheet; Deutsche Edelstahlwerke Specialty Steel GmbH \& Co. KG: Krefeld, Germany, 2020.

45. Foller, M. A new investigation on mechanical properties of ferro-titanit. In Proceedings of the 6th International Tooling Conferece, Karlstadt, Swede, 10-13 September 2002; pp. 1373-1389.

46. CPM 10V: Datasheet; Zapp Materials Engineering GmbH: Ratingen, Germany, 2016. 
47. Furuya, Y.; Matsuoka, S.; Shimakura, S.; Hanamura, T.; Torizuka, S. Fatigue Strength of Ultrafine Ferrite-Cementite Steels and Effects of Strengthening Mechanisms. Met. Mat. Trans. A 2007, 38, 2984-2991. [CrossRef]

48. Hamada, A.S.; Karjalainen, L.P. High-cycle fatigue behavior of ultrafine-grained austenitic stainless and TWIP steels. Mater. Sci. Eng. A 2010, 527, 5715-5722. [CrossRef]

49. Chawla, N.; Shen, Y.-L. Mechanical Behavior of Particle Reinforced Metal Matrix Composites. Adv. Eng. Mater. 2001, 3, 357-370. [CrossRef] 